\title{
An Analytical Model for Strategic Promotion of Growth-Oriented Women Entrepreneurship in Rural Nepal
}

\author{
Chhitij Bashyal*, Tara P. Panthi** \\ Daayitwa, Lalitpur, Nepal \\ *cbashyal@gmail.com, **tpanthi@gmail.com
}

\begin{abstract}
Entrepreneurship promotion initiatives in Nepal have paid limited emphasis on helping the growthoriented micro-enterprises transform into small enterprises. There is also a lack of knowledge and effort in customization of entrepreneurship promotion strategy to meet specific needs of entrepreneurs, particularly for women. This formative study seeks to explore such gaps and also propose an ecological framework to help future programs and policies to better address the issues identified. The study conducted interviews and enterprise observations of selected entrepreneurs of an enterprise accelerator program. The findings inform the development of a holistic framework for analyzing and designing growth promotion strategies across the dimensions of four Es: Entrepreneur, Enterprise, Ecosystem, and Economy. The study underlines the importance of forming a grounded understanding of key dimensions across the 4 Es while creating entrepreneurship promotion strategy.
\end{abstract}

Keywords: Entrepreneurship, MSMES, Enterprise, Ecosystem, Economy, Rural Entrepreneurship

\section{Introduction}

Entrepreneurship plays an important role in poverty reduction and economic development. Existing theoretical perspectives and empirical evidence point to three big ideas. First, for structural economic transformation from a traditional to a modern sector to occur, 'entrepreneurial ability' is a critical determinant for enterprise promotion and growth of the economy (Murphy et al., 1991; Nelson and Pack, 1999; Michelacci, 2003; Gries-Naude, 2010; Hasumann and Rodrik, 2003). As such, the interventions must go beyond traditional approaches of improving skills and education to developing new strategies for kindling abilities for innovation. Second, the government's role in addressing market failures is important for enabling entrepreneurship activities and growth, particularly in assessing if existing marketcompetition or regulatory policies erode the 'innovation space' for entrepreneurial growth (Hasumann and Rodrik, 2003; Acs and Naude, 2013). Third, an entrepreneurial pursuit itself is important for expanding one's capabilities, increasing personal satisfaction and happiness, and overcoming ecological and socio-cultural barriers for social development (Sen, 2000). Although the three big ideas provide a common conceptual foundation, it is essential to critically examine specific contextual variables at the individual level and within a household, society, and nation.

In Nepal, promotion of entrepreneurship is seen as a critical tool for improving livelihoods and fostering economic growth. With onequarter of its population living below the poverty line and GNI per capita at only 790 USD (World Bank), the Government of Nepal (GoN) has identified entrepreneurship as an important tool for poverty reduction and accelerating inclusive and job-led economic growth. For instance, the five-year development plans have continually emphasized entrepreneurship promotion and have implemented a range of national-level programs: Micro-Enterprise Development Program (MEDEP), Poverty Alleviation Fund (PAF), Youth and Small Entrepreneur SelfEmployment Fund (YSEF) and so on. While most of the government initiatives have poverty reduction as the primary agenda with focus on creating and promoting micro-entrepreneurs, 
many non-government sector initiatives (Rockstart, Antarprerana, Business Oxygen, etc.) have focused on supporting small and medium entrepreneurs. However, there are two fundamental gaps in the strategies that must be addressed.

Limited strategic focus on 'graduation out of poverty': The initiatives in the Micro, Small, and Medium Enterprise (MSME) landscape have either focused on improving lives of the very poor at the scale of micro-enterprises, or in incubating and improving businesses at the scale of small and medium enterprises (SMEs). However, there is limited understanding and emphasis on helping micro-enterprises, usually operated by the poor with small economic yield, transform into growth-oriented small enterprises. Existing livelihood strategies often result in making only marginal improvements in lives, rather than becoming a transformative force for pulling people out of poverty and into sustainable livelihoods and generating wider positive externalities through innovation, market efficiency and job creation (Hashemi and Montesquiou, 2016). The entrepreneurship promotion strategies, therefore, must think beyond income generation and necessity enterprising activities, which are undeniably a starting point, and instead develop effective strategies that enable growth-oriented microenterprises graduate into more productive small enterprises.

Limited customization of entrepreneurship promotion strategy to meet specific needs of women entrepreneurs: The second gap is the limited effort in customizing entrepreneurship promotion strategies for women. While most initiatives have substantial inclusion of women, along with other marginalized groups, the strategies are often universal and do not cater to unique contextual factors under which women operate their enterprises (Sattar 2011, p63), including their gendered roles (Parasuraman; 2001), risk-taking behavior (Goffee and Scase, 1985; Greene 1999), integration within the social system (Shapero 1982), and the types of supportive policy and structures needed (Mayoux 2003).

To address these gaps, Daayitwa ${ }^{1}$ has been experimenting with an innovative communitydriven model of identifying, supporting, and promoting growth-oriented women entrepreneurs. The lessons from first phase of the Rural Enterprise Accelerator Program (REAP), which were open to both women and men, showed the need for greater customization of interventions to women entrepreneurs. The main reason behind this finding was that women entrepreneurs faced unique set of constraints in their household and society compared to men, who were deemed to be competing in the District Enterprise Challenge (DEC) from a different playing field. In addition, the constraints also prevented women from accessing support services to the same extent as men. Many women struggle to increase their visibility as entrepreneurs and grow their enterprises. This unequal growth and visibility between men and women is a problem of national and international concern because inclusive growth is a key stepping stone toward overall poverty reduction and socio-economic prosperity of Nepal. With this view, a new program was designed catered to the needs of the women: Women Rural Enterprise Acceleration Program (WREAP). The program was implemented in the Palpa district of western Nepal.

\section{Methodology}

\subsection{Rationale}

The strategic gaps identified in the previous section have not been studied well in the context of Nepal's MSME sector. There is a lack of conceptual underpinning to explore the nature of these gaps and their implications on project design, implementation and impact. A grounded approach in investigating these issues helps develop critical insights into what drives microentrepreneurs, especially the growth-oriented, to operate, persevere through, and scale up their enterprises; how transformation pathways may manifest; and what strategic options must be considered by policy planners and project designers to catalyze the transformative process. The study is designed to explore such questions with top growth-oriented women entrepreneurs, selected through a district-wide competition organized by Rural Enterprise Acceleration Program (REAP) of Daayitwa. This study specifically sought to take a formative approach, using qualitative methods, to help develop a strategic framework for promoting growth-oriented women entrepreneurs. The

\footnotetext{
${ }^{1}$ Daayitwa, a non-profit organization based in Nepal, works in entrepreneurship promotion. www.daayitwa.org
} 
study specifically seeks to answer the following key questions in the process:

- What are the key qualitative dimensions and features in an enterprising ecosystem of growth-oriented women entrepreneurs?

- What aspirations drive women entrepreneurship?

- What personality/traits are most common among highly-driven women entrepreneurs?

- What are the key economic, financial, behavioral, cultural challenges and difficulties affecting women entrepreneurs in the district of Palpa?

- How are women situated in enterprising ecosystem of Palpa, particularly in the context of (a) access to gender-sensitive financial services, (b) access to gender-sensitive business development services, (c) access to markets and technology and (d) representation of women entrepreneurs and participation in policy dialogue?

- What are existing resources and actors that play a role in addressing key challenges and difficulties affecting women entrepreneurs in Palpa?

- How are women entrepreneurs' challenges and difficulties similar to and different from those of men entrepreneurs?

- What is a common pathway in growth trajectory, particularly in starting from lowscale micro-entrepreneurship?

- What strategic opportunities are present in promoting growth-oriented women entrepreneurs?

- What would a strategic framework look like that helps program and policy planners devise effective strategies for promoting growthoriented women entrepreneurs?

\subsection{Study Design}

The study employs a qualitative research method to explore aspirations, experiences, and needs of women growth-oriented entrepreneurs selected through the rigorous process of District Enterprise Challenge (DEC) as part of the implementation of WREAP. The ecological model is adapted based on the Daayitwa's "4Es" framework for strategizing and planning interventions across the enterprising ecosystem, namely (a) entrepreneur, (b) her enterprise, (c) the ecosystem consisting of the value-chain and other market actors, and (d) the economy, i.e. the macro-economy, geo-political actors and other national and international factors.

The primary data collection involved using research guide to interview entrepreneurs and observe their enterprise and business processes. Observation notes and transcripts were produced from this stage for analysis. Embedded research was conducted with the top three entrepreneurs from previous REAP programs to more closely understand the business processes and more sensitive factors, which might not come out through standard methods of inquiry. The purposive sampling allowed us to select the following participants:

- Seven growth-oriented women entrepreneurs who were selected as top 10 women entrepreneurs by the jury of experts in WREAP program

- Seven growth-oriented women entrepreneurs who were selected as top 20 but were not selected as Top 10 by the jury of experts in WREAP program

- Three growth-oriented men entrepreneurs who were selected as top 3 by the jury of experts in a previous REAP program

The characteristics of sampled participants is presented in the chart below:

\begin{tabular}{|c|c|c|c|c|c|c|c|}
\hline \multirow{2}{*}{\multicolumn{2}{|c|}{ Characteristics }} & \multirow{2}{*}{$\begin{array}{l}\text { WREAP All } \\
(\text { Top 40) }\end{array}$} & \multicolumn{2}{|c|}{ WREAP Top 20 (Excl. Top 10) } & \multicolumn{2}{|c|}{ WREAP Top 10} & \multirow[t]{2}{*}{ Total Samplec } \\
\hline & & & Total & Sample & Total & Sample & \\
\hline \multicolumn{2}{|l|}{ Overall } & 40 & 10 & $7(70 \%)$ & 10 & 7 (70\%) & 14 \\
\hline \multirow{4}{*}{$\begin{array}{l}\text { Enterprise } \\
\text { Category }\end{array}$} & Agriculture & 14 & 4 & $2(50 \%)$ & 5 & $5(100 \%)$ & 7 \\
\hline & \begin{tabular}{|l|} 
Goods \& \\
Handicrafts
\end{tabular} & 4 & 2 & $2(100 \%)$ & 2 & $1(50 \%)$ & 3 \\
\hline & Livestock & 20 & 4 & $3(75 \%)$ & 2 & $1(50 \%)$ & 4 \\
\hline & Services & 2 & 0 & 0 & 1 & $0(0 \%)$ & 0 \\
\hline
\end{tabular}




\subsection{Limitations}

Identification of growth-oriented entrepreneurs for the study sample would have been a tremendous challenge had it not been for the WREAP program (and previous REAP programs), which had done so already through a rigorous process incorporated in the District Enterprise Challenge (DEC). Hence, the qualitative study was easier to conduct, and the sampling technique only required picking entrepreneurs to represent key differences, i.e. whether participants were selected in the top 10 or not, the type of enterprise (i.e. agriculture, goods, livestock or services), and whether they were male or female (by comparing with men entrepreneurs from previous REAP program). Because growthoriented entrepreneurs are known to be in low number in a district, it is fair to assume that DEC was successfully able to identify all, if not most, of the growth-oriented entrepreneurs in the district, and the representative sampling done for the study is not sufficient to make population-wide conclusions. Nonetheless, it is likely that some growth-oriented entrepreneurs may not have been captured through the DEC. Aside from the sampling-related considerations, given the qualitative and interpersonal approach to data collection, some information may only be partially accurate. Some measures were taken with field researchers to build confidence with respondents, especially in asking for sensitive information such as enterprise strategies, financial management, and personal challenges in the household.

\section{Results}

\subsection{Promoter and inhibitors of women entrepreneurs' growth-orientation}

Self-perception and confidence of women entrepreneurs' own status in their household and their ability to do "gendered" physical tasks can diminish their conviction for growth. Vocational or technical knowledge seems to boost confidence and capability, even in absence of adequate formal education. Ability to manage time between enterprise work and other responsibilities in household and/or society can be restrictive. Interest in pursuing leadership roles in the community-based committees or cooperatives is high among top growth-oriented entrepreneurs. The family may be supportive, unsupportive or restrictive in women's entrepreneurial pursuits. Members of the society, such as other women in informal circle, neighbors, and community may dismiss or discourage the experimentation with entrepreneurship.

\subsection{Importance of business and management skills for enterprise growth}

A systematic approach in strategy and planning is largely missing in most microenterprises. Human resource for labor intensive agriculture and livestock-based enterprises is scarce due to increasing outmigration. Financial literacy and management skills are highly valued since most enterprises do not have a functional record-keeping system or practice. Enterprises that can pose negative consequences in the environment (such as farms that use pesticides) require specialized management skills and environmental safeguarding knowledge. Technical capability needs can vary by the sector, such as agriculture, livestock, goods or services. Primary sources of financial resources are local cooperatives or savings groups which make access to small loans only a minor issue. Enterprises established in areas that lack necessary ecological resources, such as drying water sources for irrigation, face systemic constraints in growth.

\subsection{Efficient interfaces with ecosystem actors for nurturing growth}

The ecosystems, under which the entrepreneurs and enterprises operate, have inefficiencies and constraints along the value chains and business environment. Some ecosystems require specific services, such as market price information or monitoring demand and supply fluctuations. One major challenge encountered by some ecosystems is harmonizing competition and collaboration in horizontal linkages. The growth-oriented entrepreneurs not only value constructive competition to improve productivity and give room for innovation, but also need collaborative platforms and arrangements for collective bargaining, product marketing, and streamlining vertical linkages for reducing marginal costs and enhancing value-chain efficiencies. In addition, there is a need for leveraging the expertise of academia, research institutions, technology service providers, and 
more experienced entrepreneurs for efficient use of resource and knowledge optimization in the ecosystem.

\subsection{Enabling macro-economic and regulatory environment for enterprise growth}

Due to top-down approach to policy making, entrepreneurs and enterprises have difficulty in influencing the policy-level factors, a strong mediatory role from the system-level actors such as the Federation of National Cottage and Small Industries is lacking. Given the volatile politicaleconomic system of Nepal, the ecosystem-level associations must campaign for a commitment from political system to avoid policies that hinder operations of enterprises. Similarly, there is still dearth of research and evidence at the local level to guide policy and program planning process at the higher levels. Even with ongoing programs and projects, the capability to implement services and create enabling environment needs further strengthening. Other macro-economic phenomenon such as increasing out-migration has contributed to both shortage of labor supply and decreased incentive for wives receiving remittance to work.

\section{Discussion}

\subsection{Growth stages of growth-oriented enterprises}

Enterprises go through different phases in its growth path. The assessment of underlying process by which an entrepreneur decides to become an entrepreneur and start an enterprise helps identify critical determinants that shape her growth path. Popular models depicting the growth phases of enterprise are adapted forms of classical product lifecycle model with 5 stages. Churchill and Lewis (1983) have identified these 5 stages for small enterprises as: existence, survival, success, take-off, and resource maturity, Scott and Bruce (1987) have identified these stages as: inception, survival, growth, expansion, and maturity. The study proposes that a women entrepreneur's startup journey in Nepal be divided into three critical components as she ventures into an enterprise, namely inception, promotional, and growth phases. The three phases are described in this section and summarized in Figure 1 below:

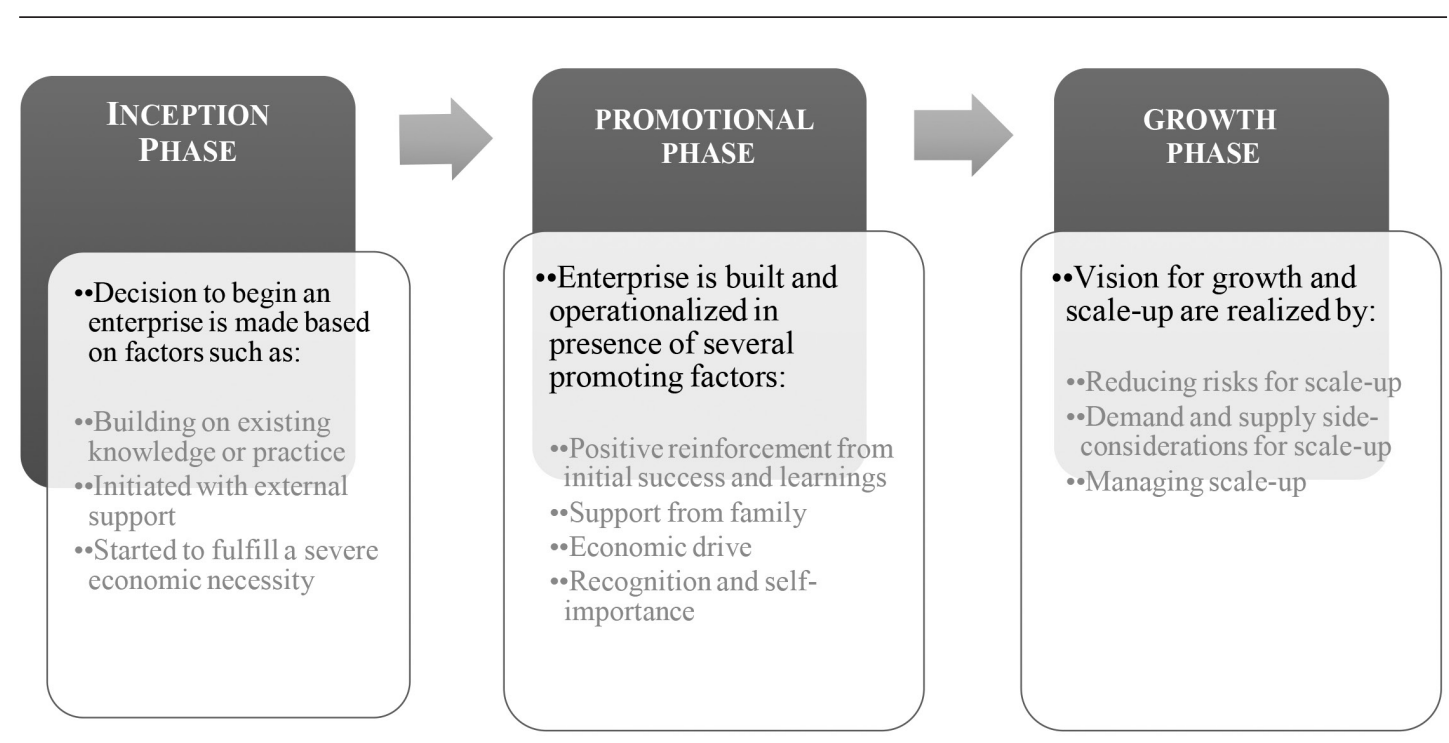

Figure 1: Three phases of the startup journey

\section{Inception Phase}

The study finds that entrepreneurs take into consideration a range of factors from one's capabilities, resources availability and gaps, financial benefits to risks to make decision to start an enterprise. While it is seemingly important to consider all these factors, the decision often 
hinges on one or more contextual factors that ultimately push the person into entrepreneurial journey, as described in detail below:

1) Enterprise built on existing knowledge or practice: It is common for rural households to be engaged in subsistence agriculture and livestock rearing. Over time, such households accumulate local knowledge to assess ecological and technical prospects of activities such as growing vegetables and rearing goats or chicken. When such knowledge and practices are catalyzed by additional technical capability building efforts, such as through local NGOs or extension services, the person can venture into a specialized area of product (such as goat farming as illustrated by a goat entrepreneur who now raises 15 goats):

"We had around 4-5 goats at home already, and then we thought of expanding it further and turning it into an enterprise. Also, I took a four day-long goat keeping training 2 years ago from District Women and Children Development Office, where I was given one goat for free. In the training, I learnt about different breeds of goats, diseases, and types of forage grass. What other trainings have you taken? I did not take any other except the 4 days goat keeping training. I chose this because the location of our house is suitable for livestock farming as there are plenty of places for grazing. So, I felt that it would be easier for me to keep goats."-An entrepreneur of Palpa district

2) Enterprise initiated with help from external support: A more common factor for starting an enterprise is receiving start-up support from local NGOs, such as International Development Enterprise (IDE), District Women and Children Development Office etc., or from governmental programs, such as the Department of Cottage and Small Industries (DOCSI). Some common forms of support include provision of trainings (such as in non-farm products like hand loom or dhaka accessories and clothes), and supply of saplings (for lemon entrepreneurs) or seeds (for vegetable entrepreneurs).

3) Enterprise started to fulfill a severe economic necessity: While most entrepreneurs are driven by the financial gains, some specially chose to venture into entrepreneurship out of economic needs to make ends meet. Such households often have issues such as an alcoholic husband who does not contribute much to the household income, unsupportive in-laws, or limited assets for productivity. The entrepreneurs are often driven by their desire to provide better education to their children and improve their own financial independency.

I was compelled to start this. My children were young and my husband is an alcoholic. If their husbands were working hard and doing well, women wouldn't have to suffer as much.

I really wanted to study but my father got me married when I was still in grade 7. So I couldn't continue my studies. Even though I couldn't study further, I felt that my children should get good education. That's why I wanted to do this... I acted very brave and didn't bow down in front of any one. I said, "I should be allowed to work to be able to get my father-in-law's medicine. If I don't get I will go elsewhere and work. Either give me a leave, or let me do farming".

\section{Promotional Phase}

Once the decision is made, the hard work of operationalizing the enterprise begins. This phase is characterized by multitude of challenges that often test entrepreneur's technical and adaptive capabilities to solve problems, seek support, and persist towards a set vision. The study finds a range of promoting factors that enable an entrepreneur to deal with such issues, as described in detail below:

1) Positive reinforcement from initial success and learnings: The initial results of enterprise are critical for one's motivation and determination to continue the entrepreneurial pursuit. The positive reinforcement can come in the form of improved earnings, increased productivity, realization of potential for scale, and increased attention from agricultural extension service providers. In contrast, when the initial optimism is met with continued external issues, entrepreneurs are compelled to discontinue, as in the case of a lemon farmer who switched from vegetable farming in response to problems caused by wild animals.

After seeing myself succeed, I constructed a tunnel. Then even the personnel from District Agriculture Office started coming to my place to 
visit... When we began vegetable farming, and started earning some money, I felt encouraged to do more. So, I made a tunnel and from that $I$ added more and more tunnels. Now I have 7 tunnels!

I was getting good results from tomato and cauliflower farming, but gradually, there was increasing problems from rabbits, deer, and monkeys all day. As they did that, I thought of an alternative and tested out a few lemon saplings in my nursery. We had one plant already, and after examining the saplings, they gave really good results. Then I realized that this is really suited for this location, and soil. So, I decided to change from vegetable farming because of wild animal problem and switched to lemon farming as an alternative

2) The support from family: For an entrepreneur to continue her aspirations, an enabling household environment seems critical. While most women entrepreneurs are expected to carry out household chores, from preparing meals to helping children, the level of support from family, particularly from the husband is important in order to devote significant time on the enterprise. Two types of support are common: (a) direct support, in which family supports directly by giving time for the enterprise, such as in going to buy raw materials, seeds and cattle feed or taking products to markets; or (b) indirect support, in which family helps in reducing the household chores for the entrepreneur so that she can devote more time to her enterprise. In cases of single mothers, the situation is rather dire, often requiring the entrepreneur to balance both household and enterprise-related responsibilities. The following quotations demonstrate such differences:

Being a woman, my additional role is also that of a housewife. So, I have to look after kids, cook, and manage forage for livestock and so on. I am also a fulltime teacher in a school nearby. I teach LKG kids. At home, there is my husband and my in-laws. I help-out in the mornings and evenings, and go to school during the daytime. My husband helps me out at home...

My children were young and my husband is an alcoholic. If their husbands were working hard and doing well, women wouldn't have to suffer as much. There wouldn't be a need for them to go abroad. So we have to work hard because they don't do that.

I have to look after my home as well as the shop. When my husband is available, he also helps me out and sits at the shop from 7-10 a.m. So, I come after giving food to my husband and children. Also, when he comes back early from his office he sits here and I go home early, otherwise I go back directly around late evening.

3) Economic drive: Another critical promotional factor in the entrepreneurial journey is the aspiration and vision for higher economic benefits from the enterprise. Most entrepreneurs had some clear goals for the next five years, whether it was to increase the number of goats or to purchase new land to increase vegetable production. Such goals are justified based on the current results and contextual factors such as one's age, ability to find labor, the level of support from the family, and other practical constraints.

4) Recognition and self-importance: One important aspect of the entrepreneurial journey is also the local recognition, which increases their confidence and gives importance to their profession. The District Enterprise Challenge (DEC) of Daayitwa seems to increase the "celebrity" status of entrepreneurs who were selected in the Top 20 and Top 10. The entrepreneurs point to the significance of such recognition and reward for good performance in entrepreneurship, particularly for making family members more supportive towards the enterprises, getting attention from financial sectors, and receiving support from extension services. Following quotation from an entrepreneur's son and entrepreneur respectively highlight the importance of recognition:

You have shown so much determination in working even when it's difficult to find labor here. Even in Daayitwa, you have been selected in the top 40, top 20, and then in top 10 as well. Now you have to be selected in the top 5 as well. Let's increase the farm area

If everything is there, lemon, vegetables, etc., whatever is needed, I want to grow them and want people to say, "a woman like this is doing so much." I want to set my name like that. 


\section{Growth Phase}

The process and nature of growth are found to be dependent on the type of product or service. The growth prospects, definition and possible trajectory can be different depending on preference, for example, whether the entrepreneur is focused on agribusiness (such as vegetable or lemon farming), livestock (goat rearing, poultry, dairy), goods (clothing, retail shop) or services (beauty parlor). While an expansion across labor, capital, and market is common across most sectors, the aspiration and ability to grow enterprises is contingent upon several contextual factors. Below is the description of how enterprises in the study view the scale-up and growth.

1) Reducing risks before scale-up: Given the initial two phases are often fraught with high uncertainties, some enterprises focus on managing and mitigating risks so that growth can be achieved in more stability and controlled manner. As such, goat entrepreneurs, for instance, emphasize the importance of insuring their livestock first and then increasing the number of goats. In case of vegetable farmers, the experimentation of different vegetable seeds, land, farming methods, and market relationships, also provides significant learning opportunities to identify risks and potentials for growth. With shop-oriented entrepreneurs, the growth phase is informed by the understanding of customer demands, strategic markets, and relationships built with input suppliers.

2) Considerations for scale-up: While most scale-ups seek to increase revenue by ultimately increasing output, the study finds the nature by which scale-up is envisioned can be either based on demand-side or supply-side considerations.

o Demand-side considerations: Where market demands are high, the entrepreneurs can be confident on their scale-up efforts with focus on increasing production and improving the linkages with the market. Service-oriented entrepreneurs, such as those with retail shops, aspire to relocate to more urban areas or establish retail outlets in bigger cities.

o Supply-side considerations: In many cases, however, entrepreneurs face their own supply-side constraints resulting in their limited ability to meet the demand. Such considerations often include investments (on capital and machinery), labor, time shared by the family, and technical capability to manage growth. Interestingly, some entrepreneurs are hesitant to take loans from banks which tend to have strict collateral requirement with cumbersome paper work, and instead prefer to borrow from local cooperatives.

3) Managing scale-up: A successful scaleup requires that both demand and supply side constraints are adequately addressed during the scale-up process. Given the risks involved, greater support from family, technical advisory services from extension workers, and persistence in the face of challenges are critical for effective transition management.

I am thinking that since my husband has a temporary job, he can also resign from his job so that we both continuously work in this and make 500 plants. Recently, we bought more land.

My husband sold the tomatoes that I planted, and didn't give me any money. Still undeterred, I continued to pursue my goal without being let down by the lack of support.

\subsection{An Analytical Model for Entrepreneurship Promotion}

The following ecological model of entrepreneurship has been proposed for understanding entrepreneurship in context of rural Nepal. Each components and subcomponents of the model have been defined for the studied context.

\section{E1: Entrepreneur}

The entrepreneur is the individual or group of individuals who take risks and drive a business idea forward. The entrepreneur's ability to manage issues at the level of self, family, and society, dictates the progress and growth of their enterprise particularly in a context where socialcapital is critical. The issues identified at each level are:

a) Self: Since an entrepreneur is a self-driven individual, it is important to identify and enable the "self" of an entrepreneur to catalyze his/her success. Some emerging themes from the study include: 


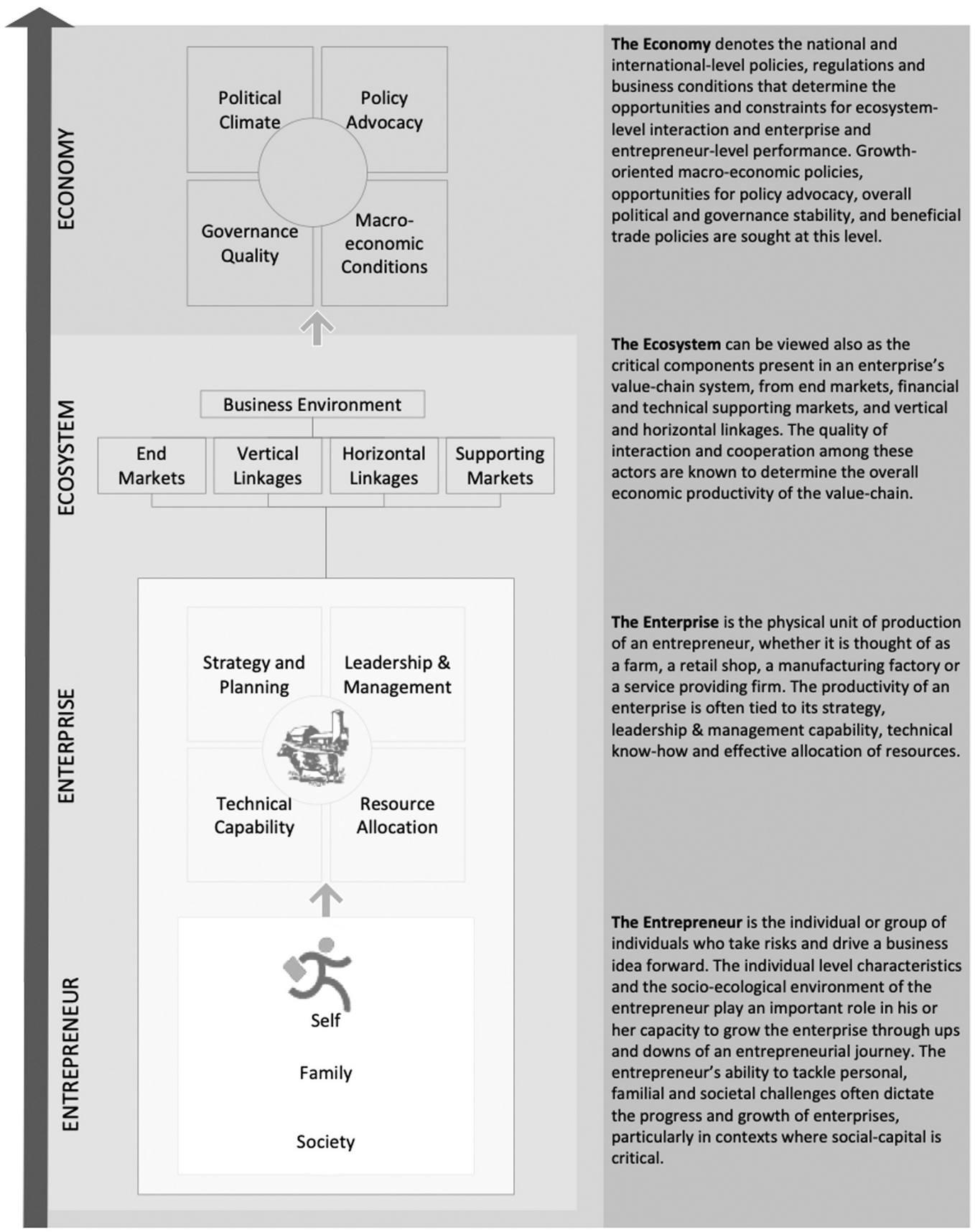

- Self-perception of women entrepreneurs' own status in their household and their physical ability to do certain tasks can often take emotional and functional toll on entrepreneurial growth.
- Vocational or technical knowledge seems to boost confidence and capability, even in absence of adequate formal education.

- Ability to manage time, between enterprise 
work and other responsibilities in household (as care provider to children and relatives) and/or society (as member of community organizations or cooperatives), is cited as one of the challenges faced by women entrepreneurs.

- Interest in pursuing leadership roles in the community-based committees or cooperatives is high among top entrepreneurs.

b) Family: The level of support from family, such as husbands, children, and in-laws, can be viewed in a spectrum of supportive, unsupportive/ discouraging and restrictive nature of the family:

\section{- Supportive:}

o Husband helps full-time or when not engaged in his work.

o Children support when available after school or during vacation

o Relatives help by bringing or taking items to market while traveling for their own purpose.

\section{- Unsupportive/discouraging :}

o Family may be indifferent, skeptical or downright discouraging about entrepreneurial work.

o Family members do not extend any support, even if they have time or resources

\section{- Restrictive:}

o Family may blame for taking too many risks or losing money in new and uncertain pursuits.

o Family may restrict access to family land or resources.

o Various cultural reasons, such as Brahmin, should not engage in poultry, may be cited to demean the enterprise.

c) Society: Following issues at the society level affect the entrepreneur's growth:

- Community's mindset towards women entrepreneurship could be discouraging, often stemming from society's perception and skepticism of women's technical knowledge, management capability, and physical ability.

- Among neighbors, some aspects of jealousy of an entrepreneur's rise are also reported. In such case, the neighbors often avoid buying goods from the services.

- Informal women circles in the community still embrace the traditional role that promotes economic dependency on husbands. Such mindset discourages women from taking risk and becoming an entrepreneur.

\section{Strategic Considerations at Entrepreneur Level}

- Build adaptive leadership capability of entrepreneurs to boost self-conviction and manage effectively familial and societal challenges in pursuing entrepreneurship.

- Provide key technical knowledge and skills to build confidence and capability to operate and grow enterprises.

- Demonstrate both economic and reputational benefits of pursuing entrepreneurship, to change mindset of unsupportive or restrictive members of the family.

- Promote entrepreneurship at a societal level such as through district-wide challenges to engage the society in selecting promising entrepreneurs.

\section{E2: Enterprise}

Enterprise is the physical unit of production of an entrepreneur, where it is a farm, a retail shop, a manufacturing factory or a service-providing firm. The productivity of an enterprise is tied to its strategy, leadership, and management capability, technical know-how, and effective allocation of resources.

a) Strategy and Planning: Most entrepreneurs have developed growth targets, identified critical constraints and planned solutions in achieving them, in various degrees and often in an ad-hoc basis, as discussed in detail below:

- Growth targets: Growth targets are described in forms of amount of earning per month, quantity of production, amount of investments, technology upgrades and expansion of labor force. 
- Constraints Diagnostics: Some of the critical constraints diagnosed by entrepreneurs range from investment gaps, labor constraints, linking to markets, information gaps and balancing family responsibilities.

- Planning solutions: Some entrepreneurs have also developed plans to mitigate constraints in their growth path. Some prefer to try experiment possible solutions while others seek to adopt best practices or knowledge.

b) Leadership and Management: The challenges discussed by entrepreneurs in relation to leadership and management fall into the following categories:

- Human resource management: The most common concern by entrepreneurs is in finding adequate labor force for the enterprise. Given the growing trend of unskilled laborers out-migration, finding khetalas, or temporary wage laborers, has become a big challenge in growth. In some cases, husbands and sons are often recruited for more physically intensive activities such as ploughing fields with a tractor.

One interesting aspect of outmigration is that while outmigration has reduced the labor force and raised the wage in general, farmers are abandoning more labor-intensive farming of crops to less labor-intensive enterprises. Another important dimension of men's outmigration is the role of remittance in also removing their wives, who now have "easy income," from the labor force. The dual impact of outmigration on the availability of both husband and wife in the labor force is causing a significant shortage of human resources for growth-oriented enterprises.

- Financial management: While most entrepreneurs reported to not have a functional record-keeping system, financial literacy and management skills are highly valued.

- Physical resource management: Making sure adequate physical resources, such as land, water, and climatic conditions are available for enterprise functioning is also one of the management concerns of entrepreneurs.
- Environmental management: Some enterprises can have negative consequences in their environment and must provision environmental safeguards. For instance, in poultry farming, neighbors and the community may complain about the smell from chicken coops and the biological waste that may pollute water and land resources. Hence, such entrepreneurs require specialized management skills and knowledge to mitigate risks to the environment and gain confidence from the neighbors.

c) Technical Capability: The type of technical capability required by enterprises varies based on the type and nature of the sector. The enterprises in the study can be classified into three sectors, with each having different kinds of technical capability requirements:

- Agriculture sector: Some primary topics for technical capability strengthening in this sector include quality seeds and nurseries, organic farming, safe farming (such as limiting use of pesticide and other chemicals), plant diseases control, setting up greenhouses and tunnels, and food processing techniques (ex: making pickles from lemons).

- Livestock sector: In the livestock sector, such as poultry, a range of topics for capability strengthening are desired, including knowledge on poultry diseases and treatment, access to quality chicks, knowledge about and access to quality feeds, skills for caring for and managing a poultry farm, and techniques for increasing productivity.

- Goods sector: Retail and goods-focused enterprises, such as in handicraft, seek to receive locally-offered trainings for improving product designs, improving quality, diversifying products, and expanding to bigger markets.

d) The ability of an enterprise to allocate resources to meet the demands of a growth strategy is critical for success. Besides human resources and technical capability resources covered above, other resources can be categorized as the following:

- Financial resources: Some of the primary sources of financial resources are local cooperatives or savings groups. While 
enterprises can take-out small loans for business growth, women-owned enterprises report facing a lack of trust, often from women themselves. Other enterprises report that access to financial resources is not the primary issue given the availability of small loans through local cooperatives.

- Land resources: In agriculture and livestockfocused enterprises, the way land is allocated and utilized determines the physical growth possibilities of an enterprise. Due to urbanization and migration, abandoned land is increasingly more available in rural areas for renting or for purchasing at low cost, whereas the valuation of land around urban areas has inflated. Changing valuation of land has both limited and enhanced capability in using land resources for enterprise growth depending on their rural or urban positioning.

- Ecological resources: Enterprises established in areas that lack necessary ecological resources, such as water for irrigation, poor climatic condition, rough terrain hindering market access and presence of wild animals that can destroy farming or livestock, face systemic constraints in growth.

- Technological resources: Another critical resource type is new technologies or equipment that increases efficiency, particularly when expanding the enterprises. For example: an expanding livestock farm might requires milking machine, pasteurizer, and packaging machine whereas a growing farm might require a green house and weather control machine.

\section{Strategic Considerations at Enterprise Level:}

- First, provide a systematic Strategy \& Business Planning support to entrepreneurs in assessing the feasibility and potential of the enterprise; developing plausible growth targets; assessing practical constraints to achieve those growth targets, and designing innovative solutions to address those constraints.

- Second, enhance essential leadership and management capability to implement those innovative solutions while managing effectively human, financial, physical, and environmental resources.
- Third, provide customized technical capability building trainings to increase knowledge and skills of enterprises to enhance operations and outputs.

- Finally, assist the enterprise in allocating resources depending on the size, growth requirements, and existing assets.

\section{E3: Ecosystem}

Ecosystem consists of enterprise's valuechain system, end markets, financial and technical supporting markets, and vertical and horizontal linkages. The quality of interaction and cooperation among these actors determine the overall productivity of the value chain.

a) End Market: The production decision of enterprises rests on the features of end markets of the product. Most micro entrepreneurs working in relatively shorter value-chain, end markets are usually the end buyers themselves, rather than an intermediary vertical unit in the value chain, such as whole-seller or retailer. Following are the crucial issues identified in end market.

- Market identification approach: Given enterprises' closeness to the customer base, they must make production and supply decision by considering several factors:

o Identify markets with excess demand over supply

o Switch to different products when oversupply can be anticipated (ex: plant beans if neighbors are planting cauliflower)

o Switch to different markets that give a higher price

- The product delivery channel: To get products to end buyers, there are three main types of channels for micro entrepreneurs:

o Direct product delivery - The products are sold by the entrepreneurs to customers directly, such as in the case of vegetables sold by entrepreneurs themselves in the market, or handicrafts or goods sold in retail shops. This channel offers reach only to local markets in proximity.

o Indirect product delivery - The products are delivered mostly through a higher vertical unit (covered in the following section), such as external retail units or intermediary 
either located in local market or town centers farther away.

o Customer pick-up - Some products are picked-up by the customers themselves, such as in the case of goat farming or poultry. This is particularly true for enterprises that have easier access to roads or offer products that are in high demand locally. As with direct product delivery, this channel only offers reach to local markets and is further limited if people are not aware of the enterprise.

\section{Critical Challenges in End Market:}

- Wastage and spoilage of agriculture products, particularly for vegetable farmers, is a critical challenge given it is the producers who must bear the loss solely if vegetables are not bought by end-buyers.

- Market-quantity demand information is not available to producer entrepreneurs to inform their decisions on production and in strategies for optimizing supplies.

- Market-price information is also lacking to assess price differences across local and farther markets.

- Market access is also limited to one's connection and networks in external markets. Those who have relatives or links in potential external markets can capitalize on those informal networks to expand their markets, whereas those who don't are stuck in local markets.

- Marketing of diversified products across sectors (ex: doing both vegetable and livestock) could create considerable challenge in developing market linkages simultaneously.

- Marketing and product advertising strategy often relies only on personal contacts or local outlets.

b) Vertical Linkages: Input supplies make up the vertical linkages in the ecosystem. Some major considerations in input supply reported across different sectors that affect the productivity and/or growth of enterprise, include the following:

- Livestock sector: For goat entrepreneurs, availability of grass is contingent upon local resources such as proximity to forest, pasture land, and planted grass. Because of the outmigration of people from villages, entrepreneurs report greater access to grassland since fields are left barren.

- Agriculture sector: The productivity and growth of agriculture entrepreneurs are depended on timely availability of good quality seeds and fertilizer, and on access to other inputs such as irrigation, labor force and pesticides.

- Goods sector: For an entrepreneur producing incense, raw materials come from an urban city, located a two-hour bus ride away. Given the transportation cost, she finds it more attractive to buy a machine herself that can produce certain raw materials. Similarly, transportation of raw materials can be challenging, particularly for women entrepreneurs with difficulty finding time away from family to go to input suppliers located in far urban centers.

c) Horizontal linkages: Horizontal linkages are defined by the nature of competition and collaboration among entrepreneurs with same or similar products described as follows:

- Competition: As there is an increase in entry of entrepreneurs in a product sector, the rising competition leads to the undercutting of prices when fighting for the same customer base. Interestingly, pioneering entrepreneurs, who have started a new product in a certain locality, seek to provide trainings to new entrepreneurs though they acknowledge it increases competition for them. While it is difficult to gauge the underlying reasons for making such a decision, some entrepreneurs do cite factors such as payment from training fees, recognition in the community as trainer, and general expansion of networks.

- Collaboration: Despite an increase in competition, some mutually beneficial opportunities from collaboration also exist, such as in reducing transportation costs when done in bulk for collective bargaining, fulfilling each other's short-run supply gaps to maintain customer satisfaction, obtaining technical trainings, and using financial services by forming community or savings groups. 
d) Supporting Market: Financial providers and technical providers that make up supporting markets have the following observations:

- Financial providers: Entrepreneurs prefer to use different forms of financial providers based on several factors including the stage of enterprise, size of investment requirements, availability of "free money" or personal savings, ability to provide collateral, and fear of defaulting on loans, as illustrated below:

The landscape of financial demand-level and supply-source can be represented in the following spectrum diagram:

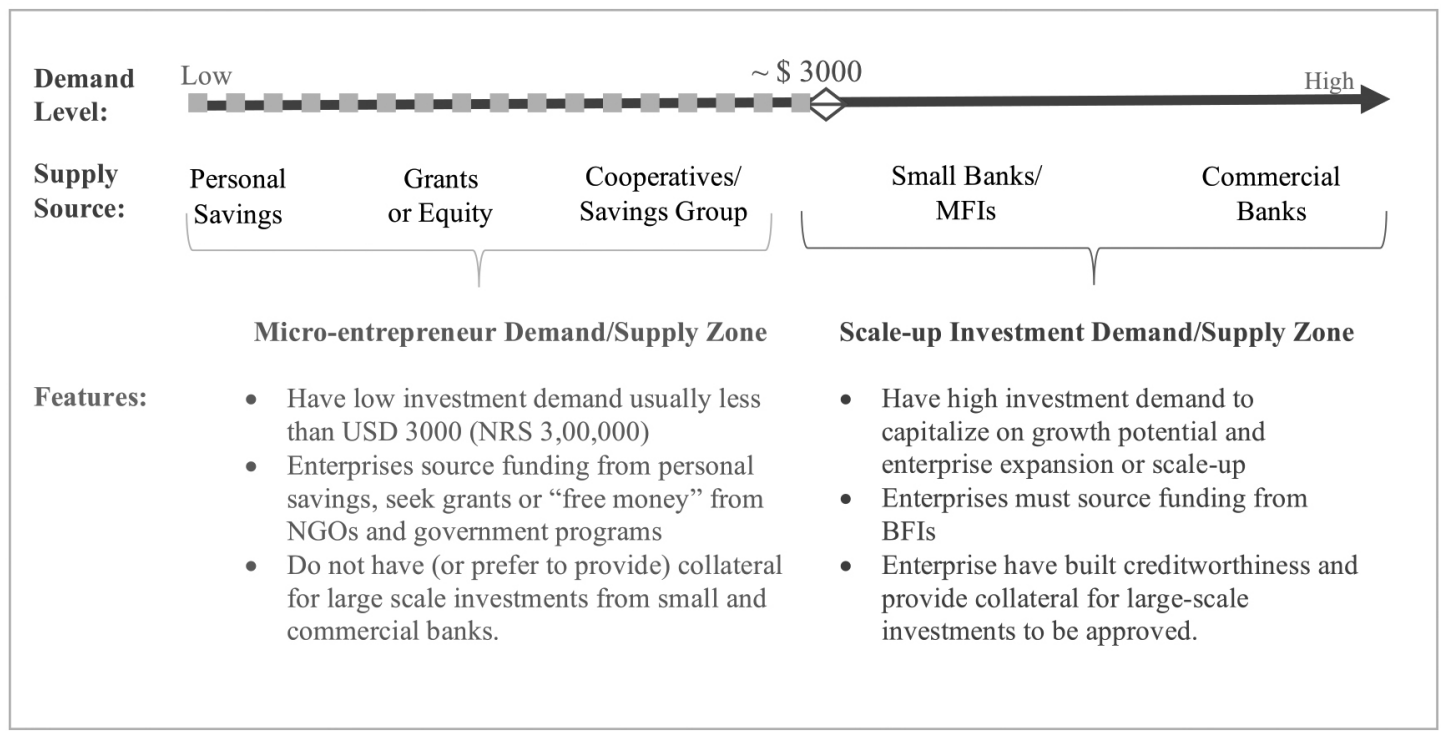

- Technical Providers: A range of technical service providers is noted to have supported the entrepreneurs in acquiring knowledge, skills and services related to their enterprises. Some of the commonly cited resources include the following:

o Government: Local Agricultural Support Center, Junior Technicians/Assistants (JT/ JTAs), i.e. agriculture extension workers

o NGOs/INGOs: Agriculture programs that provide short trainings; Campaigns that recognize and reward pioneering farmers; Training of trainers program (12 days long) to create local-level trainers in agriculture

o Community-based organizations: Farmers' groups, often link with external partners and specialists to trainings to its members (participants are often selected in competitive basis among group members); Local cooperatives o News and Media: TV and radio programs

o Peers: Learning from other farmers who are pioneering new techniques or technologies; Informal trainings from or apprenticeship with relatives or household members

e) Business Environment: Some of the common challenges cited in a business environment include the following:

- Political protests and strikes that interfere with business operations and transportation of products and raw materials.

- Legal policies that exclude micro-enterprises from receiving services, such as in restrictions in getting insurance for goats if the enterprise is raising less than 50 goats.

- The availability and quality of public services through livestock office and agriculture support center. 


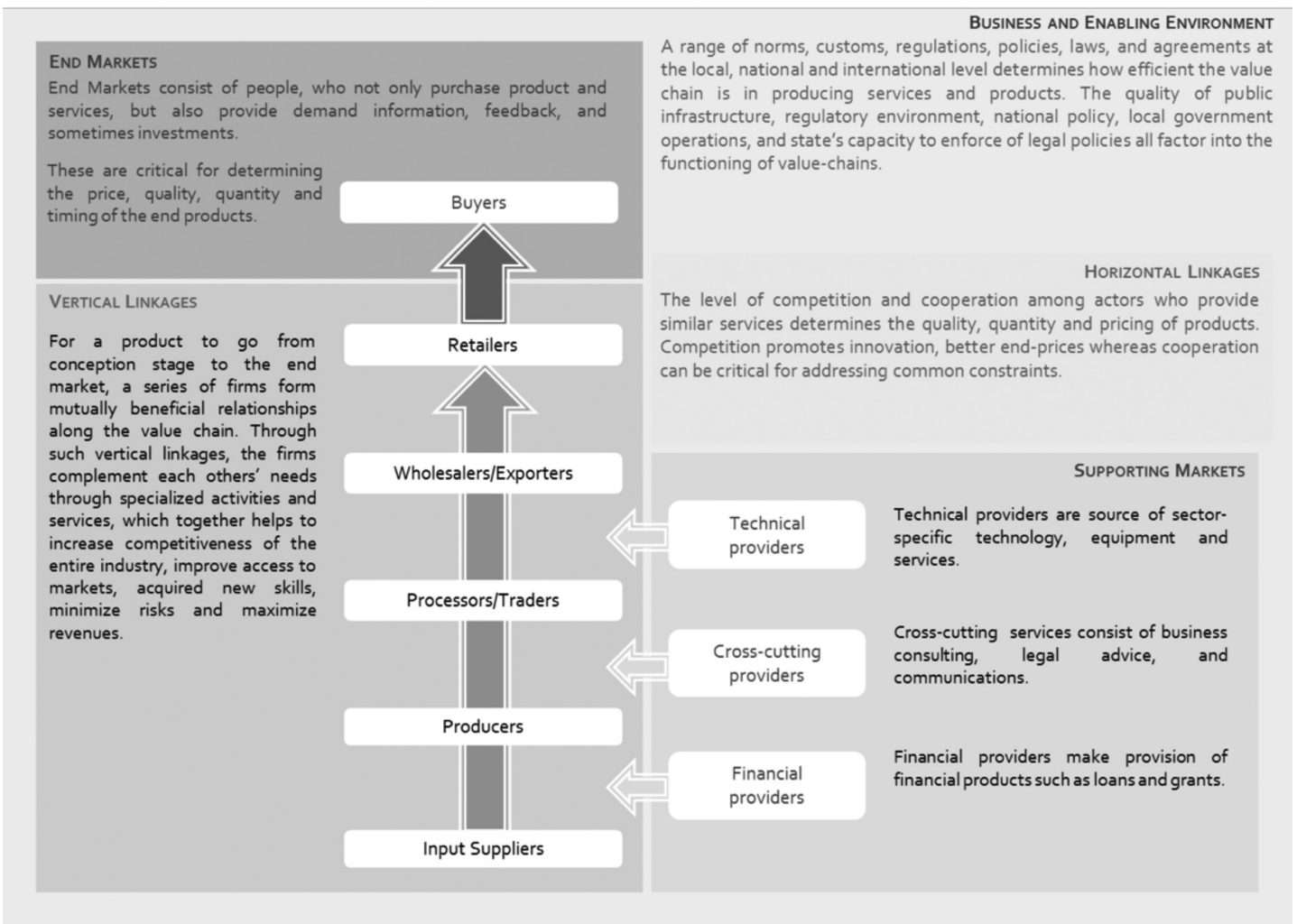

Strategic Considerations at Ecosystem Level:

- Perform a Value-Chain Analysis (VCA) at the ecosystem level to understand the various features of the different dimensions of the ecosystem.

- Provide access to price information of relevant markets to help entrepreneurs sell their products at higher profits.

- Consider social networks and relationship with end buyers in building customer relationship and identifying practical productive delivery channels given that the enterprise-customer relations are often tied to social institutions and relationships in rural areas.

- Promote constructive competition by enabling market forces to improve productivity and by facilitating collaboration in collective bargaining, streamlining vertical activities for decreasing marginal costs, and in enhancing specific value-chains.

- Facilitate local-mentorship to aspiring entrepreneurs by skilled entrepreneurs through provision of incentives and technical resources for trainers.

- Conduct sector-specific or productspecific diagnostics as part of the VCA to understand the constraints across vertical linkages. To solve the challenges, sectorspecific interventions must come from (a) the government side (such as checking the quality of inputs available, improving landuse regulations, and increasing access to fertilizers) and (b) the private sector (such as allowing competition among input providers, women-entrepreneurship friendly transportation facilities, and better resource management). 
- Assess and plan supply and demand matching of financial services with ecosystem interventions such as increasing 'creditworthiness' of entrepreneurs; reducing asymmetric information on entrepreneurs to financial providers; facilitating engagement and interaction; support scale-up investments and borrowing from small and commercial banks depending on growth potential and current stage; build action-oriented partnerships with range of ecosystem actors for enhanced resource and technical expertise optimization, such as mapping and coordination of technical services to be provided in a fiscal year by various actors; using of mass media for providing technical information; and peer-to-peer learning through local mentorship and knowledge/ skills-sharing engagements.

- Diagnose and identify policy level bottlenecks and facilitate policy advocacy efforts to entrepreneurs and/or policy planning support to institutions.

- Mitigate risks associated with political and governance instability.

- Support institutional capacity development efforts of local service agencies.

\section{E4: Economy}

Economy denotes the national and international-level policies, regulations, and business conditions that determine the opportunities and constraints for ecosystemlevel interaction and entrepreneurs and enterprise-level performance. Growth-oriented macro-economic policies, opportunities for policy advocacy, overall political and governance stability, and beneficial trade policies are sought at this level.

a) Political Climate: The most cited challenge in enterprise operation was the impact of protests and bandhs, i.e. shutdown of markets and transportation mediums, called for political reasons. Similarly, it is also noted that services or funding is often provided to entrepreneurs who are connected to the people offering those services.

b) Policy Advocacy: One of the major challenges in advocating for policy is the limited number of entrepreneurs in a sector to collectively raise voice. Pioneer entrepreneurs, experimenting new ideas and sector, can face constraints from existing policy framework. However, since they are the pioneers they cannot build a base for policy advocacy or have the time or resource to lobby for changing a growthhindering policy.

c) Governance Stability: The quality of government services, provision of entrepreneurship support and training, and general responsiveness of the government extension services is impacted by the stability and accountability of governance system both at the national-level policy planning and local-level program implementation.

d) Macro-Economic Conditions: Interest rates, inflation level, and general economic productivity and purchasing capacity are known to impact the financial outputs of the enterprises. Interestingly, women entrepreneurs did not cite any macro-economic level challenges that they faced.

\section{Strategic Considerations at Economy Level:}

- Encourage national-level campaigns through existing entrepreneur associations to receive commitment from political parties to avoid tactics that hinder operations of enterprises.

- Facilitate policy advocacy by gathering evidence through research and making policy recommendations to policy stakeholders.

- Build governance capability and extend support for more stable and quality provision of services.

- Monitor the impact of macro-economic factors on enterprises, and make evidence available for policy advocacy.

\section{Conclusion}

The formative study has helped develop a strategic framework for promoting growthoriented women entrepreneurs by distilling critical features across the dimensions of 4Es and in their growth trajectory.

First, in regards to first E, Entrepreneurs, a greater emphasis is needed in adaptive aspects of 
entrepreneurial capability. This means strategies must go beyond the traditional technical skillbuilding approaches to techniques that help address issues and challenges originating from the individual, household (or family), neighborhood, and/or society. The respondents report the constraints posed by such variables in their entrepreneurial pursuits. Therefore, to provide a holistic support to the entrepreneur, it is important to ensure motivation for growth is sustained, necessary interpersonal and adaptive problemsolving capabilities are developed, and technical ability and sector-specific knowledge is enhanced.

Second, in regards to Enterprise, the entrepreneurs must operate as per a systematically designed strategy \& business plan. The exercise helps an enterprise assess the feasibility and potential of the enterprise, develop plausible growth targets, assess practical constraints to achieve those growth targets, and design innovative solutions to address those constraints. Likewise, micro-enterprises must build their leadership and management capability to implement those innovative solutions while managing effectively human, financial, physical, and environmental resources. In this process, supporting markets have a strong role to play in providing customized technical capability building trainings.

Third is the Ecosystem, under which the entrepreneurs and enterprises must duly identify inefficiencies and diagnose and resolve critical constraints along the value-chains and business environment. Some ecosystems require specific services, such as market price information or monitoring supply and demand fluctuations. One major challenge encountered by some ecosystems is harmonizing competition and collaboration in horizontal linkages. The evidence suggests that growth-oriented entrepreneurs not only value constructive competition to improve productivity and give room for innovation, but also need collaborative platforms and arrangements for collective bargaining, product marketing and streamlining vertical linkages for reducing marginal costs and enhancing valuechain efficiencies. In addition, ecosystem must also leverage the expertise of academia, research institutions, technology service providers, and more experienced entrepreneurs for enhancing resource and knowledge optimization.

Finally, since entrepreneurs and enterprises have more difficulty in influencing the Economylevel factors, a strong mediatory role must be played through the ecosystem-level actors. Given the volatile political-economic system of Nepal, the ecosystem-level associations must campaign for a commitment from political system to avoid tactics that hinder operations of enterprises. Similarly, there is still a dearth of research and evidence at the local level to guide policy and program planning process at the higher levels. Even with ongoing programs and projects, the capability to implement services and create enabling environment needs further strengthening.

In conclusion, the study underlines the importance of forming a grounded understanding of all dimensions across the 4 Es while creating entrepreneurship promotion strategy. The strategic framework is not only useful in designing interventions for promoting women entrepreneurship, but also in identifying critical gaps in research and evidence. The 4Es framework, for instance, can help develop more rigorous quantitative models for testing attributions, designing experimental studies to test effectiveness of specific or "packaged" interventions, and in guiding future operations research of projects such as REAP. A holistic strategy, backed by strong scientific evidence, is necessary to catalyze women-entrepreneurs in growing their enterprises and enhancing their enterprising ecosystems.

\section{Acknowledgments}

We would like to express our sincere appreciation to the women entrepreneurs who participated in the study and provided valuable inputs and warmly greeted the research team into their homes and enterprises. Special thanks to Lakshyana KC and Vibustuti Thapa for conducting many of the interviews and transcribing notes diligently, Meenu Maharjan from Daayitwa and Krishna Kala Bhanadai from REAP Palpa for organizing and managing the field visits. We would also like to thank Dr. Pukar Malla and Ms. Sabrina Singh for their valuable inputs in planning the study. 


\section{References}

Churchill, N.C and Lewis, V.L. (1983, May). 'The five stages of small business growth', Harvard Business Review, May 1983, Retrieved from https://hbr.org/1983/05/the-five-stages-of-small-businessgrowth

Das, D.J. (2000). 'Problems faced by women entrepreneurs', Das, D.J (2000), "Problems faced by women entrepreneurs" in K.Sasikumar (ed.), Women Entrepreneurship, New Delhi, Vikas Publishing House

Goffee, R. and Scase. R. (1985) Women in charge: the experiences of female entrepreneurs, London: Unwin Hyman

Greene, P. (1999) 'Exploration of the Venture Capital Industry: Is Gender an Issue?', Frontiers of Entrepreneurship Research

Greene, P., Brush, C., Hart, M., \& Saparito, P. (1999), "Exploration of the venture capital industry: is gender an issue?”, In P.D. Reynolds, W.D. Bygrave, S. Manigart, C.M. Mason, G.D. Meyer, H.J. Sapienza, \& K.G. Shaver (Eds.) Frontiers of entrepreneurship research (pp. 168-181). Wellesley: Babson College.

Gries, T. and Naudé, W.A. (2010). Entrepreneurship and structural economic transformation, Small Business Economics Journal, 34(1), 13-29.

Hashemi, S.M., Motesquiou, A. (2016) "Graduation Pathways: Increasing Income and Resilience for the Extreme Poor.” CGAP Brief. The Consultative Group to Assist the Poor. Retrieved from: http:// www.cgap.org/sites/default/files/Brief-Graduation-Pathways-Dec-2016.pdf

Hausmann, R. and Rodrik, D. (2003). Economic development as self-discovery, Journal of Development Economics, 72(2), 603-33.

Mayoux, L.(2003, September), From marginalisation to empowerment: towards a new approach in small enterprise development, SDC employment and income division workshop, Small Enterprise Development and Empowerment, Gerzensee, Switzerland

Michelacci, C. (2003). Low returns in R\&D due to lack of entrepreneurial skills, The Economic Journal 113 (484), 207-225.

Murphy, K., Schleifer, A. and Vishny, R. (1991). The allocation of talent: Implications for growth, Quarterly Journal of Economics, 106(2), 503-30.

Nelson, R.R. and Pack, H. (1999). The asian miracle and modern growth theory, The Economic Journal, 109(457), 416-36.

Parasuraman, S. (2001). Type of employment, work-family conflict and well-being: a comparative study', Journal of Organizational Behaviour 22(5), 551-568.

Sattar, S. 2011. Opportunities for men and women: emerging Europe and Central Asia. Washington, DC: World Bank. Retrieved from: http://documents.worldbank.org/curated/en/479131468250293544/ Opportunities-for-men-and-women-emerging-Europe-and-Central-Asia

Scott, M. and Bruce, R. (1987). 'Five stages of growth in small business', Long Range Planning, Vol. 20, No 3, pp. 45-52

Sen, A. (2000). Development as Freedom. New York: Anchor Books

Shapero, A. (1982) 'The social dimensions of entrepreneurship', in V. Kent Sexton (ed.) Encyclopedia of entrepreneurs, New Jersey: Prentice Hall

World Development Indicators (2017), The World Bank. Retrieved from http:// databank.worldbank.org/data/views/reports/reportwidget.aspx? Report _ Name $=$ CountryProfile \&Id=b450fd $57 \&$ tbar $=y \& d d=y \& i n f=n \& z m=n \&$ country $=N P L$ 